\title{
Gedikbulak Okul Binasının Sismik Performansı Hakkında
}

\author{
Mehmet Sefa ORAK ${ }^{1}$ \\ Zekai CELEP $^{2}$
}

\section{ÖZ}

23 Ekim ve 9 Kasım 2011 tarihlerindeki Van Depremleri sonrasında çok sayıda bina hasar görmüştür. İstanbul Teknik Üniversitesi, Deprem Mühendisliği ve Afet Yönetim Merkezi uzmanlarından oluşan bir ekip depremde hasar gören birçok binanın hasar seviyelerini inceleyerek kullanılabilirlik durumları hakkında raporlandırma yapmıştır. Gözlemler sırasında en dikkat çekici durumlardan biri Gedikbulak okul binasını incelerken meydana gelmiştir. $\mathrm{Bu}$ durumun sebebi o bölgede toptan göçmenin oluştuğu tek kamu binasının olmasıdır. Sahadaki gözlemler ve daha sonradan ulaşan bilgiler, binada taşıyıcı sistemi oluşturan kolon ve kirişlerin yanında birbirine dik iki doğrultuda uzanan perde duvarların mevcut olduğunu ortaya koymaktadır. İncelenen okul binası Milli Eğitim Bakanlığı tarafından uygulanmış örnek projelerden biri benimsenerek inşa edilmiştir. Bu yazıda saha gözlemlerinden ve Milli Eğitim Bakanlığı arşivlerinden elde edilmiş bilgiler 1şı̆̆ında Gedikbulak okul binası sonlu elemanlar yöntemi ile modellenip analizi yapılmıştır. $\mathrm{Bu}$ çalışmada doğrusal ve doğrusal olmayan yöntemler kullanılmış olup çerçeve elemanlarda plastik mafsal kabulü ve perde duvarı modellenmesinde kullanılan kabuk elemanlarda lif kabulü yapılarak analizler yapılmıştır. Analizlerden elde edilen sonuçlar ile saha gözlemleri karşılaştırılıp yorumlandığında önemli tasarım eksikliğinin olduğu binalarda karmaşık yöntemler ile performans değerlendirmesi yapılması yerine bu şekildeki binalarda bazı basit kabuller ile güçlendirme yapılabileceği vurgulanmak istenmiştir.

Anahtar Kelimeler: Betonarme, Van Depremi, hasar değerlendirmesi, okul binası.

\begin{abstract}
Seismic Performance of Gedikbulak School Building Revisited

After the Van Earthquakes of October 23 and November 9, 2011 a large number of buildings were damaged. A team of experts from the Istanbul Technical University, the Earthquake Engineering and Disaster Management Center investigated numerous buildings including schools to determine their damage levels and to decide whether they can be used further for education purposes. One of the most remarkable field inspections was observation of the damages in the Gedikbulak School building which has been the only
\end{abstract}

Not: Bu yazı

- Yayın Kurulu'na 20.04.2015 günü ulaşmıştır.

- 30 Haziran 2017 gününe kadar tartışmaya açıktır.

1 İstanbul Teknik Üniversitesi, İnşaat Mühendisliği Bölümü, İstanbul - orakm@itu.edu.tr

2 İstanbul Teknik Üniversitesi, İnşaat Mühendisliği Bölümü, İstanbul - celep@itu.edu.tr 
school building even the only public building experiencing total damage. The site observations and collected information reveal that the building had several shear walls located in two directions besides columns and beams. The building had been constructed by adopting one of the sample projects of the Ministry of Education. However, site observations have shown that the concrete quality and workmanship used in the building were quite poor. In this paper, the damage records of the building obtained from the field observations are given and the structural system is modeled and analyzed by adopting the structural layout obtained from the archives of the Ministry of Education. The study is carried out by using the linear and nonlinear analysis by employing plastic hinge assumption in the columns and fiber assumption in the shear walls. Seismic performance assessment of Gedikbulak school building is studied in view of the design shortcomings and the maximum earthquake effects. Numerical results are compared to field observations. Finally, design recommendations and seismic evaluation of school buildings are presented.

Keywords : Reinforced-Concrete, Van Earthquake, damage assessment, school building.

\section{GİRIŞ}

Deprem yönetmeliklerinde okul binaları, konut binalarına göre daha yüksek düzeyde sismik güvenlik gerektirir. Bunun nedeni olarak okul binalarının deprem ile göçmesi sonucu çok sayıda can kayıplarının oluşmasının önlenmesi yanında okul binalarının depremden sonra geçici barınak olarak kullanılması olarak gösterilebilir. 23 Ekim-9 Kasım 2011 Van depremi $\left(\mathrm{M}_{\mathrm{w}}=7.1\right)$ sonucunda birçok okul binası farklı seviyelerde hasar görmüştür [1]. Aynı zamanda herhangi bir hasar meydana gelmeyen okul binaları da mevcuttur. Ancak, Van Depremi, Van bölgesi için kabul edilebilir tasarım depreminin altında olması, bu binaların hepsinin gerekli deprem güvenlik seviyesine sahip olduğunu göstermez [2]. Bu nedenle, okul binaları için belirlenen ilgili bina önem katsayısı da dahil olmak üzere tasarım depremi dikkate alınarak okul binalarını değerlendirmek ve yeterli dayanıma sahip olmayan yapısal sistemlerin deprem güvenliğini artırmak önemlidir. Genel olarak, sismik etkiler göz önüne alınmadan tasarlanmış binalarda, kiriş açıklık donatılarının mesnet kısımlarında süreksizliği ve geniş etriye aralıkları gibi önemli eksiklikler vardır. Tasarım eksikliğinin yanı sıra, binaların yapısal taşıyıcı sisteminin düzeni sismik davranışı için önemli bir faktördür. İncelenen Gedikbulak okul binasında da, yetersiz malzeme ve iş̧̧ilik kalitesinin yanı sıra asimetrik olarak yerleştirilen perdeler binada rijitlik merkezi ile kütle merkezini uzaklaştırarak binada burulmaların oluşmasına sebep olmuştur.

Gedikbulak okul binası şehir merkezine $45 \mathrm{~km}$ mesafede ve merkez üssünden $13 \mathrm{~km}$ uzaklıkta yer almakta olup, deprem sonucu toptan göçmenin oluştuğu tek kamu binasıdır. Yazarlar, Van depreminin etkilerini araştırmak üzere saha gözlemlerinde bulunarak yapı hakkında bilgi edinmişlerdir. Deprem etkisi sonucu, betonarme çerçeve elemanlarının yıkıldığı okul binasında bazı akslar arasındaki dayanım olarak yüksek perdelerin yıkılmayıp ayakta kaldığı gözlenmiştir. Şekil 1'de görüldüğü üzere deprem sonucu okul binasının yıkılmasının en önemli sebeplerinden biri binanın rijitlik merkezi ve kütle merkezi arasında büyük bir dışmerkezlik bulunmasıdır. Diğer taraftan Şekil 3'de beton kalitesinin uygun granulometriye sahip olmadığı ve betonda ayrışmanın da mevcut olduğu görülmektedir. Yeterli donatı varmış gibi görünüyor olsa da, yakın bir incelemeden sonra donatının oldukça yetersiz olduğu belirlenmiştir. 

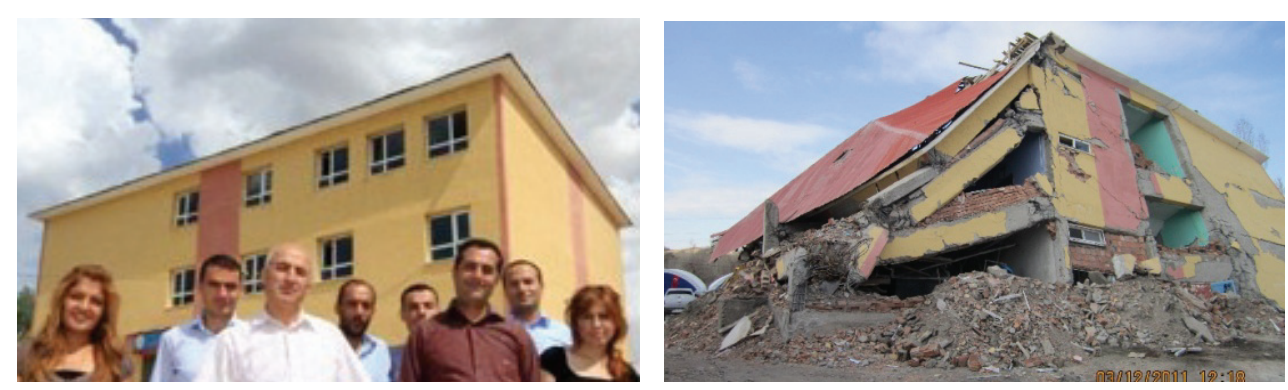

Şekil 1. Deprem öncesi ve Ekim 2011 Van depremi sonrası Gedikbulak okul binasından görüntüler

\section{BINANIN TAŞIYICI SISTEMI}

Gedikbulak okul binası Milli Eğitim Bakanlığı tarafından yapılan tipik kırsal alan okul projelerinden biridir. Ancak, bölgede belirli bir süre sonra uygulanmasından vazgeçilmiştir. Bina, üç kattan meydana gelip taban oturum alanı $322 \mathrm{~m}^{2}$, dir. Binanın taşıyıcı sistem ve mimari projeleri kısmen bulunabildiğinden, projelerde sadece taşıyıcı sistem boyutları elde edilebilmiş olup, donatı bilgisi mevcut değildir (Şekil 2).

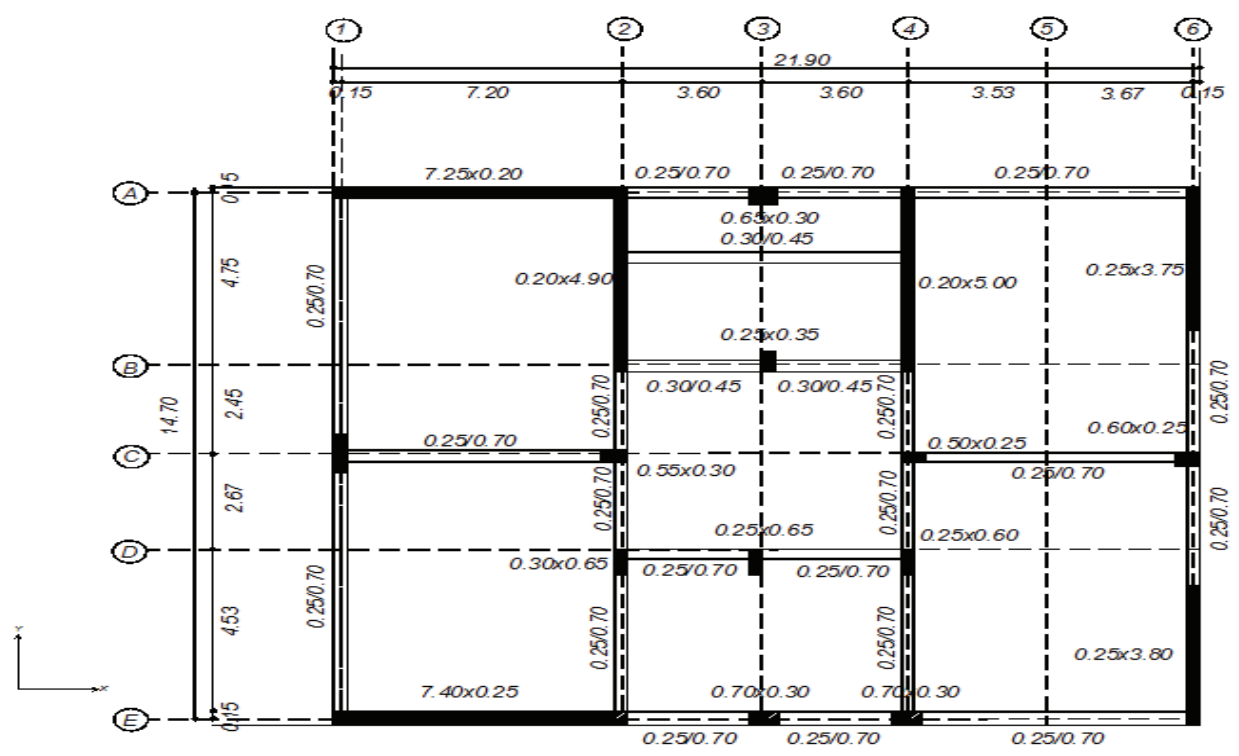

Şekil 2. Gedikbulak okul binasının taşıyıcı sistem planı (boyutlar m cinsindendir)

Kat yüksseklikleri eşit olup 3.20m'dir. Binada betonarme döşeme kalınlıkları 0.12m'dir. Birbirine dik her iki doğrultuda asimetrik olarak planda yerleştirilen perdeler kirişler yardımıyla çerçeve sisteme bağlanmıştır. İncelenen bina hakkında yeterli bilgi olmasa da, 
DY-1975 [3] göre tasarımının yapıldığı tahmin edilmiştir. Bunun sonucunda bina önem katsayısı da dahil olmak üzere toplam ağırlığın \%15 kadarı yatay yük olarak göz önüne alınmıştır. Yapılan gözlemler sonucu uygun olmayan granulometri kullanılması sebebiyle beton malzeme kalitesinin düşük olduğu belirlenmiştir. Bunun yanında çok farklı agrega boyutları kullanılmasından dolayı taşıyıcı sistemde hem düşük ve hem de düzgün olmayan bir dayanım dağılımı mevcuttur. Binada düz donatının kullanıldığı gözlemler sonucu belirlenmiştir. Binanın deprem etkisi altında davranışını belirlemek için analitik hesaplarda donatı kalitesi S220 $\left(\mathrm{f}_{\mathrm{y}}=220 \mathrm{MPa}\right)$ ve beton kalitesi C20 $\left(\mathrm{f}_{\mathrm{c}}=20 \mathrm{MPa}\right)$ kabul edilmiştir. Aynı zamanda farklı beton kaliteleri için de parametrik bir çalışma yapılmıştır. Mimari projeden yararlanılarak kullanım amacına ve hesaplara uygun sabit ve hareketli yükler seçilmiştir. Yapının zati yüküne ek olarak, kaplama yükü $1.5 \mathrm{kN} / \mathrm{m}^{2}$ ve hareketli yük olarak $3.5 \mathrm{kN} / \mathrm{m}^{2}[4]$ göz önüne alınarak hesaplar yapılmıştır. Binada betonarme taşıyıcı elemanlarda DY-1975 uygun olarak minimum donatı oranları kullanılmıştır.
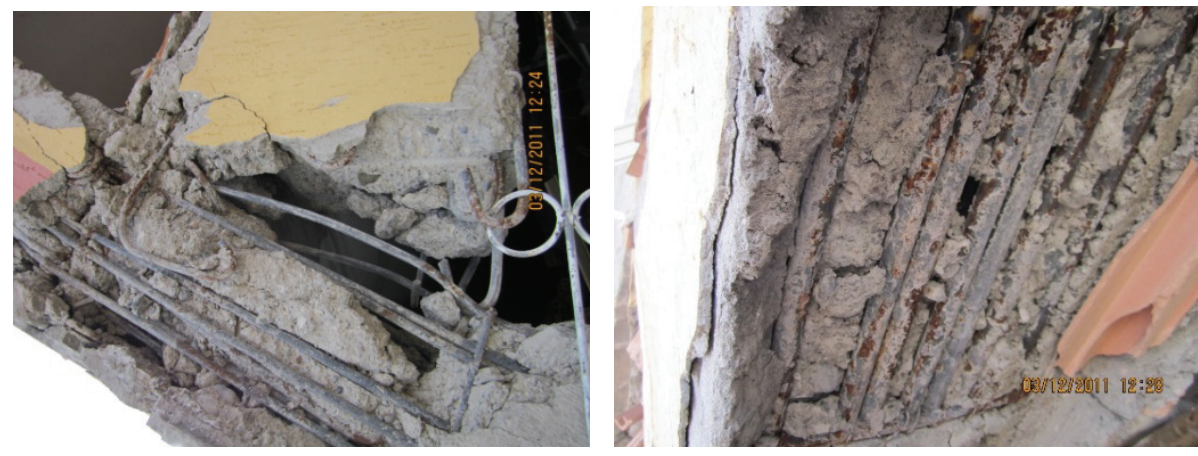

Şekil 3. Saha gözlemlerinden elde edilen kolon-kiriş birleşim bölgesi fotoğrafi

\section{GEDİKBULAK OKUL BİNASI YAPISAL MODELI}

Gedikbulak okul binasının deprem etkisi altında yapısal davranışını incelemek üzere sonlu elemanlar programı SAP 2000 (CSI, 2003) [5] yardımıyla analitik modeli oluşturulmuştur. Şekil 4'den görüldüğü üzere çerçeve elamanları olarak kolon ve kirişler çubuk eleman, mevcut perdeler de kabuk eleman olarak modellenmiştir. Yapılan analizlerde göz önüne alınan yükler TS-498'e uygun olarak seçilmiştir. Taşıyıcı sistemde doğrusal ve doğrusal olmayan analizler yapılmış olup sonuçları karşılaştırılmıştır. Doğrusal hesapta tüm elemanlar lineer elastik davranış göstermekte olup, doğrusal olmayan hesapta çerçeve elemanlarda deprem etkileri sonucu gerilme yığılmalarının oluştuğu kritik kesitlerde plastik mafsal kabulü [6] yapılarak çözüm yapılmıştır. Perdelerin doğrusal olmayan davranışı da lif kabulü yapılarak gerçekleştirilmiştir [7]. Ancak, doğrusal olmayan hesaplarda perdelerin tasarım depremi etkisinde elastik kaldığı ve şiddetli deprem etkisi altında da sınırlı doğrusal olmayan deformasyon oluştuğu söylenebilir. İncelenen binada analiz sonucunda 1. Mod için periyot değeri $0.203 \mathrm{~s}$ (kütle katılım oran $1 \mathrm{x}=\% 12$ ve $\mathrm{y}=\% 66$ ), 2. Mod için periyot değeri $0.141 \mathrm{~s}$ (kütle katılım oranı $\mathrm{x}=\% 39$ ve $\mathrm{y}=\% 14$ ) ve 3 . Mod için periyot değeri $0.125 \mathrm{~s}$ (kütle katılım oranı $\mathrm{x}=\% 1$ ve $\mathrm{y}=\% 0$ ) olacak şekilde hesaplanmıştır. 


\section{OKUL BINASININ PERFORMANS DEĞERLENDIRMESI}

Gedikbulak okul binasının performans değerlendirmesi için birbirine dik her iki doğrultuda

doğrusal olmayan değerlendirme yöntemlerinden Artımsal Mod Birleştirme Yöntemi kullanılmıştır. İncelenen okul binasında birinci mod için kütle katılım oranları, planda uzun doğrultuda \%66 ve planda kısa doğrultuda ise \%39 olarak belirlenmiştir. İki doğrultuda da kütle birinci mod katılım oranlarının büyük olmamasının en önemli nedeni olarak rijitlik merkezi ile kütle merkezinin ayrık olmasından dolayı binada burulmaların meydana gelmesidir. Artımsal Mod Birleştirme Yöntemi, binadaki asimetriklikten dolayı birbirine dik her iki doğrultuda pozitif ve negatif yönlerde uygulanmıştır. Yöntemde düşey yüklerden sonra yatay yükler artımsal olarak uygulanmıştır. Artımsal mod birleştirme yönteminde incelenen bina için ilk 6 Mod gözönüne alınmıştır. Statik itme eğrileri Şekil 5'de görüldüğü gibi, beton kalitesinin değişimleri göz önüne alarak her iki doğrultu için de gösterilmiştir.
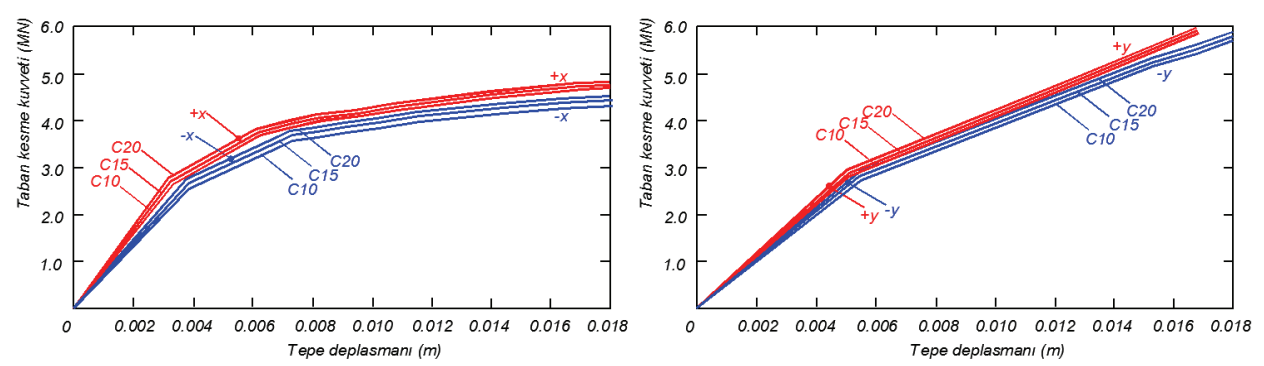

Şekil 5. Gedikbulak okul binasına ait farklı beton kalitelerine göre iki doğrultu ve iki yönde statik itme eğrileri

Yaygın olarak bilindiği gibi doğrusal olmayan çözüm sonucu elde edilen statik itme eğrileri binanın geometrik özelliklerine ve taşıyıcı sistemi oluşturan kesitlerin kapasitelerine bağlıdır. Mevcut durumda, Gedikbulak okul binasının geometrik özelliklerinin belirli olmasına rağmen, taşıyıcı sistem elemanlarında donatı ile ilgili bilgiler yönetmelikte verilen minimum donatı oranları kabul edilerek hesaplar yapılmıştır. Şekil 6 ve Şekil 7 sırası ile 50 yılda aşılma olasılığı \%10 olan tasarım depreminde ve 50 yılda aşılma olasılığ $1 \% 2$ olan şiddetli deprem etkisinde performans noktalarını göstermektedir.

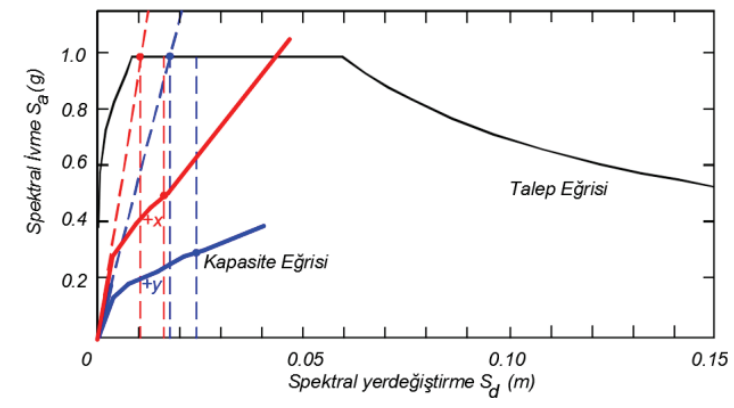

Şekil 6. TDY 2007 'e [8] göre 50 yllda aşılma olasılı̆̆ \%10 olan tasarım depremi için performans noktasinin belirlenmesi 
Gedikbulak okul binasında doğrusal olmayan Artımsal Mod Birleştirme Yöntemi sonucunda 50 yılda aşılma olasılığ $\% 2$ olan şiddetli deprem için sistemde belirlenen performans noktasında oluşan plastik mafsallar Şekil 8'de gösterilmiştir. Bu bilgiler doğrultusunda incelenen binada düşey taşıyıcı elemanların "Can Güvenliğgi" performans seviyesini sağlamadığı, bina taşıyıcı sistemindeki kirişlerin ise ilgili performans seviyesini sağladığı hesaplar sonucu belirlenmiştir. Aynı zamanda, incelenen binada 50 yılda aşılma olasılığı \%10 olan tasarım depreminde düşey taşıyıcı elemanların "Hemen Kullanım" performans seviyesini sağlamadığı, bina taşıyıcı sistemindeki kirişlerin ise, ilgili performans seviyesini sağladığı hesaplar sonucu belirlenmiştir.

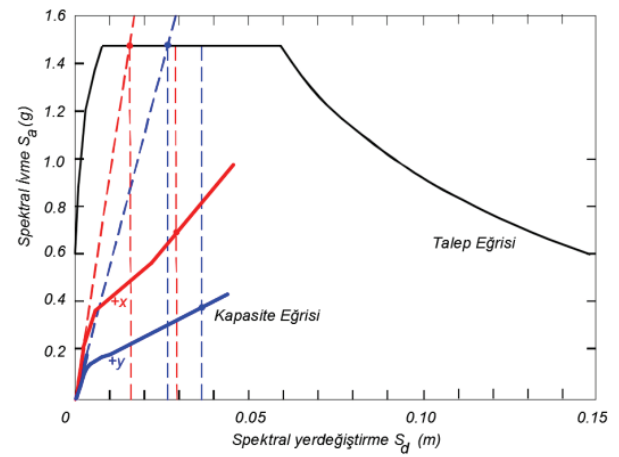

Şekil 7. TDY 2007'e göre 50 yılda aşılma olasılı̆̆ \%2 olan şiddetli deprem için performans noktasinin belirlenmesi
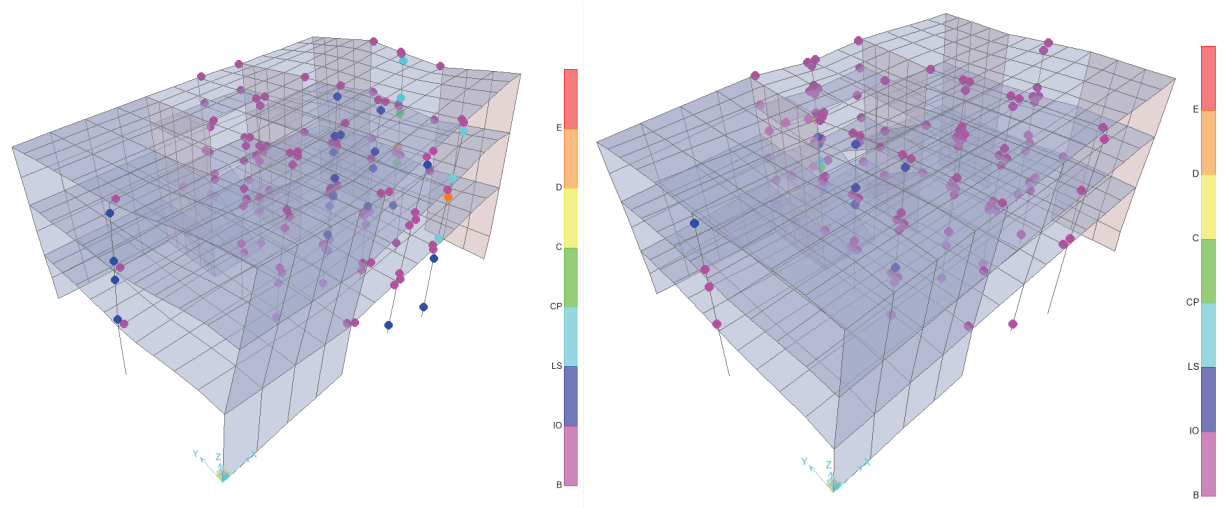

Şekil 8. Incelenen binada performans noktasındaki doğrusal olmayan deformasyonlar (sol: $x$ doğrultusu, să̆: $y$ doğrultusu)

Şekil 9'da Van depreminin spektral ivme ve spektral deplasman eğrileri ile Gedikbulak okul binasının kapasite eğrisi belirtilmiştir. Görüldüğü üzere Van depremi tasarım depreminin çok altında olduğundan binanın performans noktası kapasite eğrisinin elastik bölgesini ancak aşmakta ve sistemde çok sınırlı bir hasar oluşmaktadır. 


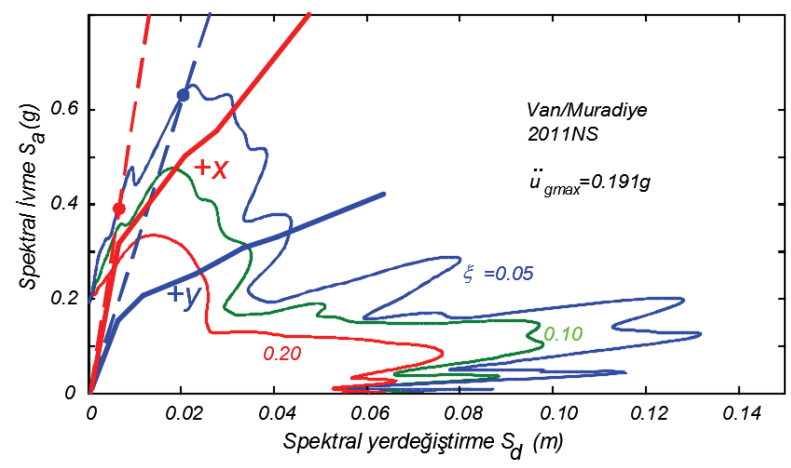

Şekil 9. Van depremi $S_{d}-S_{a}$ spektral ĕgrileri ile okul binasının kapasite ĕgrileri.

\section{SONUÇ VE ÖNERILER}

Gedikbulak okul binasının analitik incelenmesi ile aşağıdaki sonuçlara ulaşılmıştır;

a. Performans değerlendirmesi sonucunda, DY-2007'e göre 50 y1lda aşılma olasılığg $\% 10$ olan tasarım depreminde, okul binasındaki düşey taşıyıcıların "Hemen Kullanım" performans seviyesini ve 50 yılda aşılma olasılığ $\% 2$ olan şiddetli deprem etkisinde, okul binasındaki düşey taşıyıcıların "Can Güvenliği” performans seviyesini sağlamadığı sonucuna ulaşılmıştır.

b. Gedikbulak okul binasında, yapılan analizler sonucunda toptan göçmenin oluşmasının taşıyıcı sistem düzeninden kaynaklanmadığı görülmektedir. Bu yorumlar yanında Van depreminin bölgedeki tasarım depreminden önemli derecede düşük olduğu gözönünde bulundurulmalıdır. Meydana gelen deprem de ise, DY-2007 tarafindan belirlenen koşullara göre, okul binasının "Hemen Kullanım" performans seviyesini sağlamakta, başka bir deyiş̧le binanın deprem etkisi altında davranışı elastik kalmaktadır. Yerinde yapılan inceleme binanın elde edilen kalıp planında verilen ve analizlerde kabul edilen boyutlara göre inşaa edildiğini de göstermektedir.

c. Yazarlar tarafindan incelenen okul binasında toptan göçmenin oluşma nedeni olarak, düşük malzeme kalitesi ve betonda uygun olmayan granulometrinin kullanılmasını tespit etmişlerdir. Bir diğer önemli eksiklik ise, binada mevcut olan perdelerin temel, kiriş ve döşemeler ile bağlantısının uygun detay ile oluşturulmamasıdır. Benzer yetersizlikler kolon kiriş birleşimlerinde de görülmüştür.

d. $\mathrm{Bu}$ analizlerden ve saha gözlemlerinden çıkarılacak en önemli sonuçlardan biri ise, deprem sonucu oluşan hasarlarının nedeninin karmaşık olmadığı, sadece bazı basit kuralların uygulanmamasıdır. Aynı zamanda, bu sonucun sadece bu okul binası ile ilgili olmadığı, aynı sonuçların diğer binalar içinde geçerli olduğuna yazarlar tarafından inanılmaktadır.

e. Bu çalışma bir kez daha basit ve uygulanabilir düzenlemelerin önemini vurgulamıştır. Genel olarak benimsenen görüş, tasarım taban kesme kuvvetinin ve minimum donatı oranları arttırmanın ve karmaşık analizlerin yapılmasının deprem hasarlarını önemli 
derecede engelleyeceğidir. Projelerin uygun detaylar ile hazırlanması ve hazırlanan projelerin sahada kontrollü olarak uygulanmasının, daha önemli olduğuna yazarlar tarafindan inanılmaktadır.

f. Aynı şekilde, buna benzer önemli tasarım eksikliklerinin olduğu binalarda karmaşık yöntemler ile performans değerlendirmesi yapılması yerine bu şekildeki binalarda bazı basit kabuller ile güçlendirme yapılabileceği söylenebilir.

\section{Teşekkür}

Bu çalışma TÜBITTAK'ın 1649B031303975 numaralı desteği ile yürütülmüştür.

\section{Kaynaklar}

[1] Konagai K, Ulusay R, Kumsar H, Aydan Ö, Celebi M (2012) The characteristics of seismic, strong motion and structural damage of the 2011 Van-Ercis earthquake. In: Proceedings of the international symposium on engineering lessons learned from The 2011 Great East Japan Earthquake, Tokyo

[2] Bal IE, Erol G, Yüksel E, Karadoğan F, (2013). On The Seismic Performance of RC School Buildings in Van, 2013, International Van Earthquake Symposium, Faculty of Civil Engineering, Istanbul Technical University, Istanbul.

[3] DY-1975 (1975). Deprem bölgelerinde yapılacak yapılar hakkında yönetmelik, Ankara, Bayındırlık ve İskan bakanlığı; 1975.

[4] TS-498, (1997). Yapı elemanlarının boyutlandırılmasında alınacak yüklerin hesap değerleri, Ankara, TSE;1997.

[5] CSI, SAP2000 V-16 (2003). Integrated finite element analysis and design of structures; Berkeley, California (USA); Computers and Structures Inc.

[6] FEMA-440, (2005). Improvement of nonlinear static seismic procedures, Federal Emergency Management Agency, Washington.

[7] ASCE/SEI 41-06, (2007). Seismic rehabilitation of existing buildings. American Society of Civil Engineers.

[8] DY-2007 (2007). Deprem bölgelerinde yapılacak binalar hakkında yönetmelik, Ankara, Bayındırlık ve İskan bakanlığı; 2007. 